\title{
BIM-Enabled Estimating through Technology Ontology for Owners and Contractors
}

\author{
Marcel Maghiar ${ }^{1}$, Lauren Livingston ${ }^{2}$ and Avi Wiezel $^{3}$ \\ 1. Civil Engineering and Construction Management, Georgia Southern University, Georgia 30460-8077, USA \\ 2. Estimating Department, Brasfield \& Gorrie, Inc., Georgia 30144, USA \\ 3. School of Sustainable Engineering and Built Environment, Arizona State University, Arizona 85281, USA
}

\begin{abstract}
There are progressive architects, engineers, contractors and owners that adopt some of the newest technologies for financial benefits. The moving force to integrate BIM (building information modeling) tools may come from owners demanding a BIM deliverable to approve the work on these projects. If a contractor can produce this deliverable, then obtaining the project could be done in a more convincing way. Contractors are confronted with problems in selecting proper construction methods and applying their knowledge about specific and well-defined technologies to a project. Their decision-making process and better project outcomes can be improved through a database-oriented library of construction methods and therefore, a consistent methodology to classify construction methods is needed. This goal can be achieved by introducing rigorous construction method descriptors. The technology solution and the trending need of owners to pay software companies to develop software that really works for them and contractors are empirically proved in this paper through a technology ontology and BIM-enabled estimating procedure. An exploratory case study is presented. This way, owners can efficiently demand deliverables that can be utilized by them downstream, allowing contractors and subcontracting trades to work efficiently and to assure the daily flow of operations.
\end{abstract}

Key words: Owner, contractor, BIM, ontology, estimating, construction technology.

\section{Introduction}

The Architect's Handbook of Professional Practice defines detailed cost estimating as a forecast of construction cost prepared on the basis of a detailed analysis of materials and labor for all items of work [1]. Preliminary cost estimates are based on area, volume, general systems or assemblies, or similar conceptual estimating techniques when the scope is not defined. Preliminary (or conceptual) estimates are normally performed by architects and sometimes contractors. Detailed cost estimates occur when the scope of work is clearly defined. The typical design/estimate process begins with conceptual and preliminary cost estimate and evolves to the construction/definitive cost estimate.

Corresponding author: Marcel Maghiar, Ph.D., assistant professor, research fields: BIM, productivity, estimating, scheduling and lean construction. E-mail: mmaghiar@georgiasouthern.edu.
Contractors work to accurately measure and price the individual items to develop an overall cost management budget to present to the owner/client. According to Dell'Isola [1], the owners would expect that an accurately defined budget will be prepared early in a project and that the project will be completed to the required scope, meeting expectations of quality and performance, all within budget. Some owners will require a detailed estimate early in the design phase before construction begins from the construction team or designers to ensure that the project is within budget. If it is not, then the procurement process will come to a halt and the design team may be required to redesign. The owner may then require a detailed estimate to explain where and why there are cost changes. Detailed cost estimating requires a good amount of time, precision, attention to detail, consistency in methods of preparation, and knowledge of constructability. Table 1 shows the relationship of the project definition, end 
Table 1 Estimate phase comparison (adapted from design + construction strategies, Sabol [2]).

\begin{tabular}{llllll}
\hline \multirow{2}{*}{ Estimate phase } & \multicolumn{4}{c}{ Accuracy ranges } \\
\cline { 2 - 5 } & \multicolumn{2}{c}{ Conceptual } & \multicolumn{1}{c}{ Budget } & Detailed \\
\hline $\begin{array}{l}\text { End usage purpose of } \\
\text { the estimate }\end{array}$ & Screening/feasibility & Concept study & Budget/control & Control/bid tender & $\begin{array}{l}\text { Check estimate or } \\
\text { bid/tender }\end{array}$ \\
$\begin{array}{l}\text { \% of complete definition } \\
\text { Expecting accuracy }\end{array}$ & High: $30 \% \sim 100 \%$ & $20 \% \sim 50 \%$ & $10 \% \sim 30 \%$ & $5 \% \sim 20 \%$ & $50 \% \sim 100 \%$ \\
range & Low: $-20 \% \sim-50 \%$ & $-15 \% \sim-30 \%$ & $-10 \% \sim-20 \%$ & $-5 \% \sim-15 \%$ & $3 \% \sim 15 \%$ \\
\hline
\end{tabular}

usage, expected accuracy and preparation effort for each estimate phase. As indicated, the detailed estimates require or expect the highest accuracy (3\% 15\%) and take much more preparation effort. Knowledge of construction processes is very useful, especially for processes and sequences not typically drawn or detailed in construction documents, such as excavation, form work, sheeting and shoring, false work, and a variety of general conditions [1].

\section{Literature Review}

BIM (building information modeling) models can provide accurate, automated quantification and a thorough understanding of the building system as a whole. The model helps architects, engineers and constructors to visualize what is to be built in simulated environment and to identify potential design, construction or operational problems [3]. BIM models represent data-rich, object-oriented, intelligent and parametric digital representation of the facility, from which views and data appropriate to various users' needs can be extracted and analyzed to generate information that can be used to make decisions and to improve the process of delivering the facility [3].

Accuracy depends on how well developed the objects and assemblies are in the model. The method of cost calculations in the different design phases will vary because earlier phases will use a more generalized cost per linear foot and later on in the final design, estimators will derive a total area for each building material [2]. BIM models can also provide feedback to the project team at all phases of the design and construction. This is helpful when developing preliminary cost estimates for the owner because the estimator can provide feedback on the design's constructability and offer cost saving solutions. Through the use of the BIM costing exercises throughout the project, this offers the promise of reducing the need for value engineering by supporting the decision-making process with more accurate information, earlier in the project [2]. Owners will be offered better-cost savings through reduced errors in quantity take-offs as well as offering more cost efficient alternative materials and methods. Architects will be able to keep up with their design costs and insure it is staying within the budget without spending an intensive amount of time quantifying their project.

The tool developed by Cheung et al. [4] allows users to evaluate the functionality, economics and performance of buildings concurrently with building design. To illustrate the mechanics of the tool, their paper details the cost estimation module that enables quick and intuitive exploration of early stage design in a popular 3D modeling environment. Measurements are automatically extracted from 3D models and profile driven estimates are revised in real-time. Through the use of effective cost estimation software, companies can better define the expenses, prepare for labor expenses and produce a profit. A few benefits that have been found through research of 32 major projects conducted by Stanford University CIFE (Center for Integrated Facilities Engineering) were that there is up to $50 \%$ elimination of unbudgeted change, cost estimation accuracy is within $3 \%$, there can possibly be up to $80 \%$ reduction in time taken to generate a cost estimate, savings up to $10 \%$ of the contract value through clash detections, and up to $7 \%$ reduction in project time when using BIM on a project [3]. 
According to Autodesk Whitepaper, about 50\% 80\% of the time needed to create a cost estimate is spent just on quantification [5]. Therefore, it is assumed that the use of BIM provides a more thorough understanding of the design, quantifications, and cost estimation, and saves money and time as well.

\subsection{Objective of the Technology Ontology}

The researchers had established in a previous study a consistent methodology to unequivocally classify construction methods. Such a classification, called "technology taxonomy", is attaching the concept of technology to the existing construction estimating processes. The expectation for this research is to improve the decision-making process at the management level by opening the possibility to implement construction methods into a BIM-enabled estimating procedure and reducing the time and financial resources necessary in the decision-making process of the project managers' job. A well-prepared and early estimate enables the construction manager to make sound economic decisions. To prepare reliable estimates, the estimate methodology must be commensurate with the desired level of accuracy and the level of scope definition at the time when the estimate is prepared. The accuracy of any estimate depends on the quantity and quality of known information about the project. Simply put, a more precise definition yields a more accurate estimate. When scope is not clearly defined, the experience and skills of the team, and the estimators in particular have a significant impact on estimate accuracy. This research is proving that a domain of estimate optimization exists. Moreover, the technology ontology domain applied to an estimating process can have a significant impact on the accuracy of the estimate for owners and contractors. A consistent methodology to unequivocally classify and quantify any construction method, called "technology taxonomy", will be consistent with the needs of the database structures which are needed to attach the concept of technology to the existing construction estimating processes. The totality of generic attributes used in the "technology taxonomy" forms the technology ontology.

Niknam and Karshenas's paper [6] discusses how ontologies can be used to publish product information and develop ontology-based estimating applications. $\mathrm{Xu}$ et al. [7] introduced a new philosophic stance for cost estimation to address the development of model-based cost estimation addressing the importance of contextual information and the needs of extension of pricing information according to the general process of cost estimation by using the IFC (industry foundation classes) standard.

\subsection{Picture Map of Estimates and Expected Accuracy}

To review the effective methods in estimating and their life cycles, a picture map is drawn based on the project life cycle and its phases (Fig. 1).

As described above, a number of estimates are performed throughout the life of a project. These include feasibility estimates, conceptual estimates, contractor's bid estimates, progress estimates and so on. Although these types of estimates are generally known by these terms, they can vary slightly from case to case and from company to company. Furthermore, there are no clearly defined boundaries between each type. Fig. 2 presents the major types of estimates and their expected level of accuracies, based on the life time cycle of the project. The two curves represented in Fig. 2 are boundaries of the least accurate estimates and the most accurate estimates relative to the LTC (life-time cycle) of the project.

The endeavor of this research is to narrow down the domain between the two curves (to narrow the range of the curves) and to lower this range to a better level of expected accuracy (Fig. 3). Fig. 3 shows the general progression from the least to the most accurate estimating types. Better expected accuracy can be achieved through cost analyses and alternative construction methods. To improve the accuracy of the 


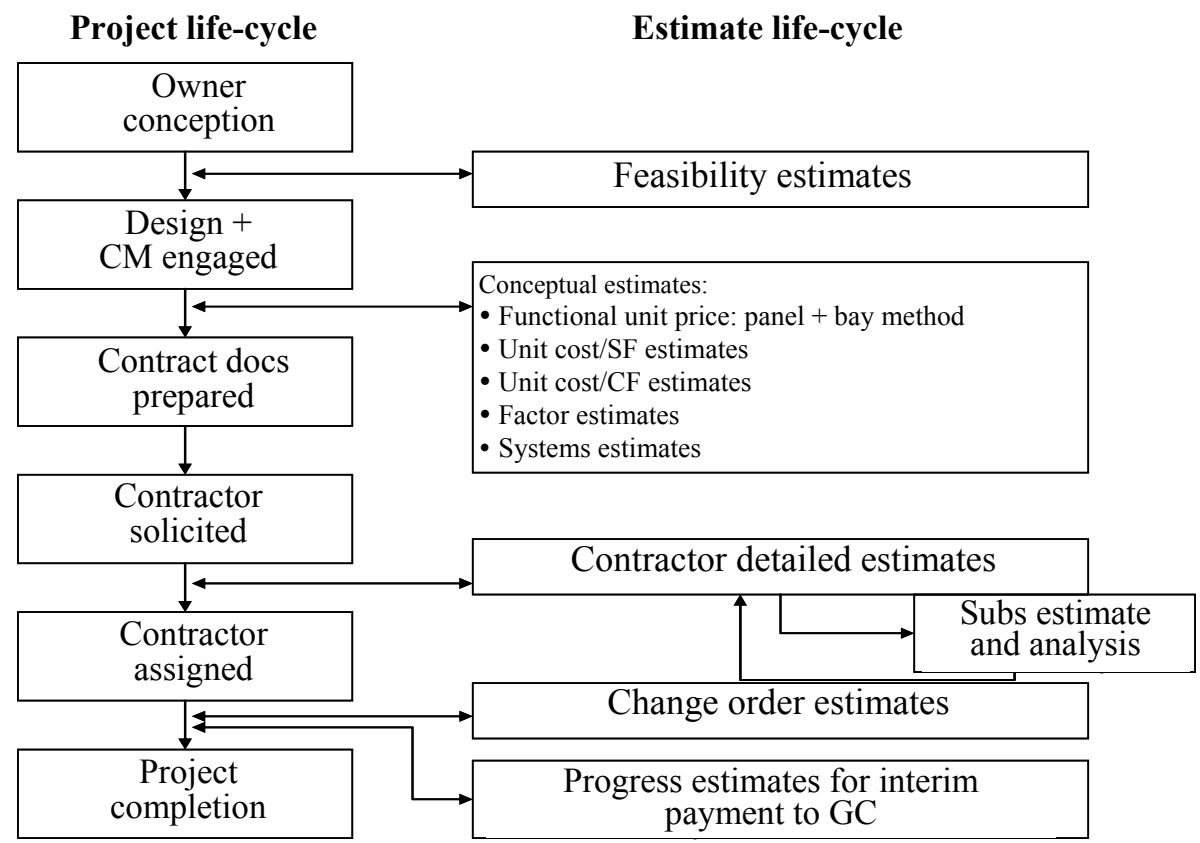

Fig. 1 Picture maps of estimates.

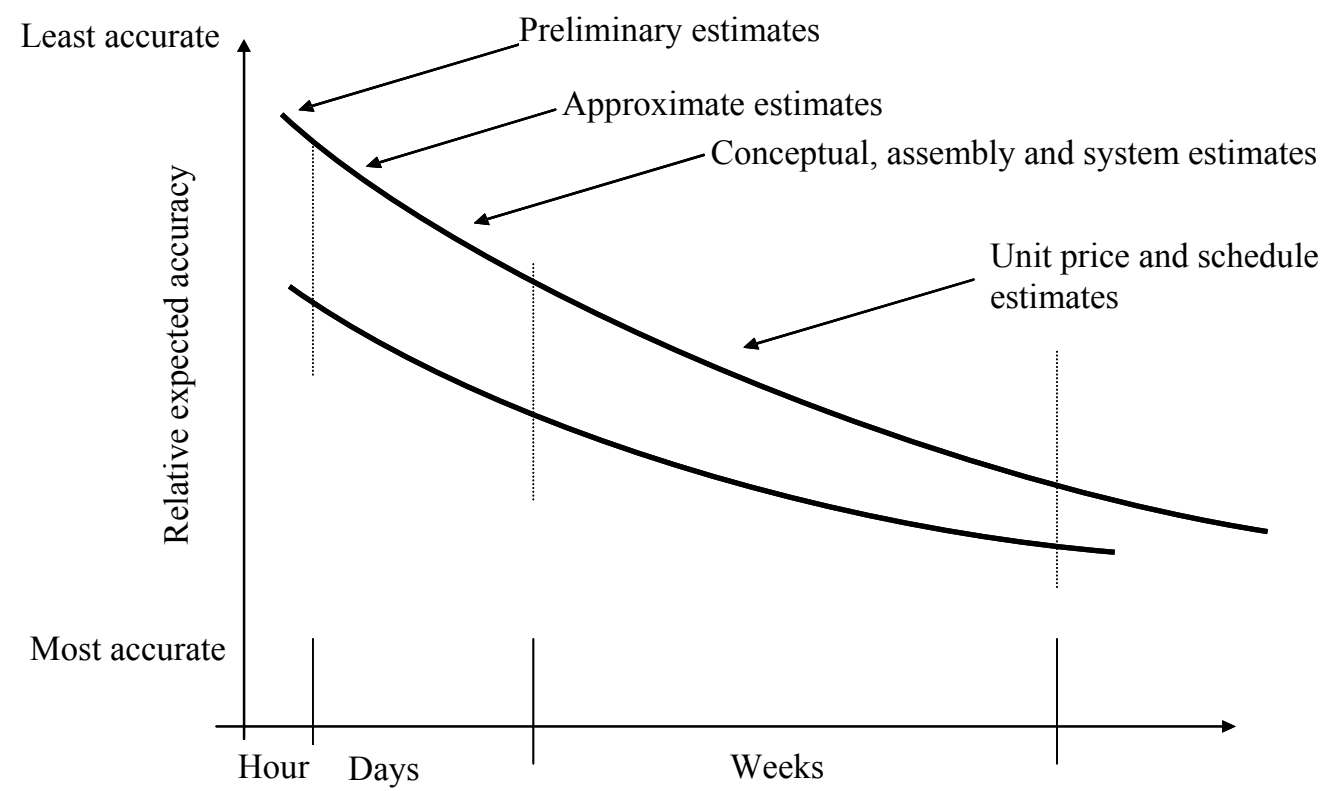

Time (LTC)

Fig. 2 Time dependency and accuracy of estimating methods.

estimates through selection of a correct technology available from a pool of technologies and assign it to the correct activity to complete a construction object (a column, a wall assembly, etc.) should be in the focus of a project manager. This information should be accessible and understandable by a computer domain knowledge that is capable to assure continuous loops until the right selection is provided against all constraints in place (physical, time or availability constraints).

On the other hand, risk assessment and assigning contingency are important tasks in preparing estimates, but they are not in the scope of this research. It is known that key members of project management decisional level must provide input to assess risk properly and to assign contingency, based on the expected level 


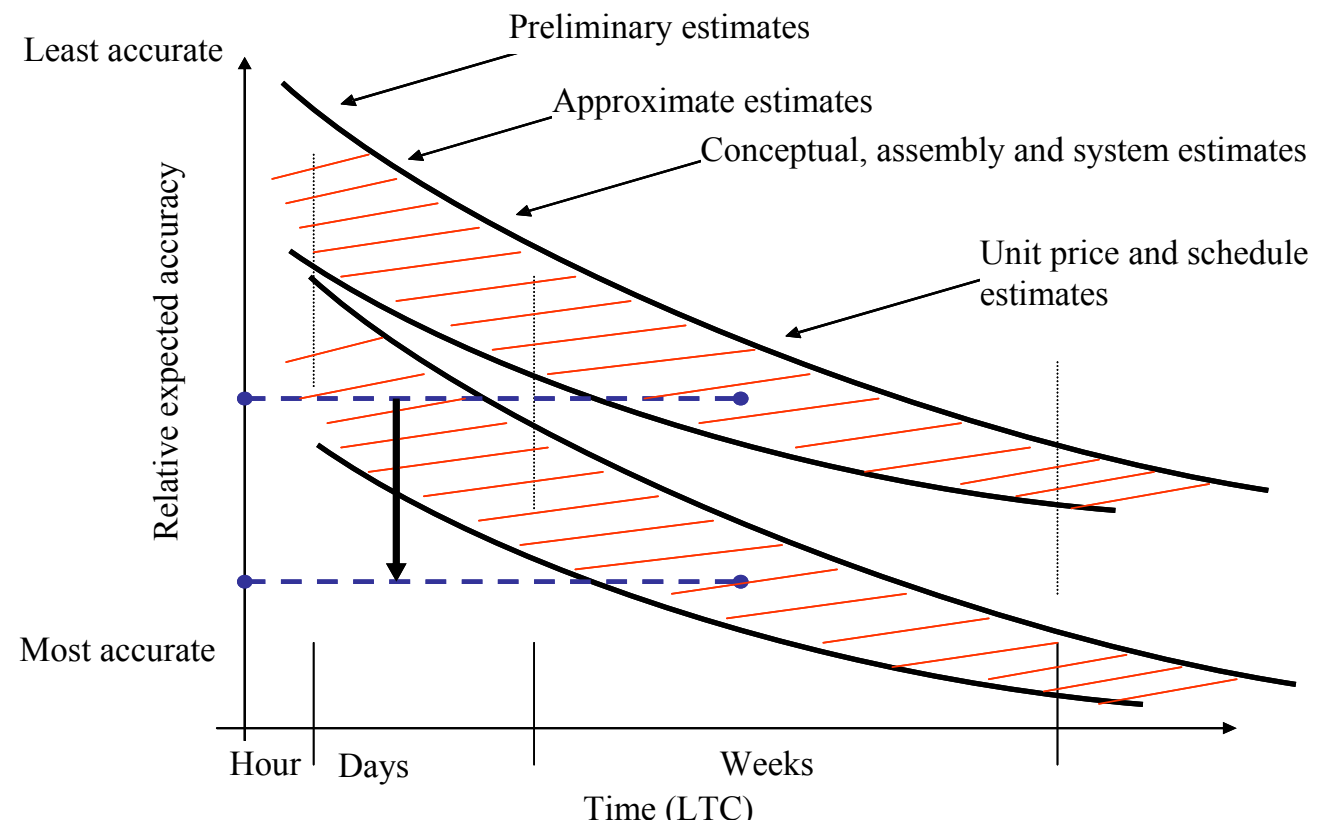

Fig. 3 Relative expected accuracy in the selection of the method process.

of estimate accuracy. Utilizing structured techniques to determine contingency reduces prejudice, which improves estimate accuracy. The estimator must select the appropriate construction method from a pool of possible methods. Furthermore, selection of the methodology and methods applicable to the estimation process can save the time and money that are needed in this process and possibly salvage in the preconstruction and during the construction phases. Allowing the cost quantifying to be associated with the right technology needed in a particular project can generate savings and better organize company's resources.

Therefore, this is the essential purpose of technology ontology in estimating. This process analysis associated with a generated digital representation of a virtual building may reduce the cost and overall duration of the project. Consequently, time and money can be saved by obtaining more accurate estimates supported by decisions about using the appropriate construction methods.

In this study, the authors did not consider change orders or claim estimates-only factors involving resources (material, labor and equipment) and different techniques that can shape a construction method. Also, uncertainty analysis and some value engineering are not considered because they do not fit in this generalized picture. Thus, speaking in more generalized terms, a construction method is considered a function generated by resources $(\mathrm{M}$-materials, L-labor, E-equipment) and techniques (Eq. (1)).

$$
\text { Construction Method= }
$$

The estimator's job is to fully consider the products and the processes in the building process, and attach a cost to them with as much accuracy as possible during the lifetime of the project. Construction managers' and estimators' job experiences are constantly challenged by the selection of the methods that need to be applied to activities during the effective process of building, which turn around to the specificity of the available technologies in the respective organization and applicability of these technologies to construction methods.

\subsection{Ontology Development-Technologies}

Both construction methods and techniques use available resources in a company setting. Activities, 
which are basically generated by the changes in geometry of the product, are required to use methods that are capable of producing the intended product. For example, a cast in place concrete column needs to have forms in place, which can be made of plywood, aluminum, steel, plastic or timber. There are different techniques of how to use and attach this formwork: first use, second use, with tie wires, with steel ties, etc. (Table 2).

In the process of estimating, all resources are quantified and received a price per unit.

Each method will have at least one resource, i.e., an individual, identifiable and more importantly chargeable item that contains price and consumption data. There are five types of resources: work, material, subcontractor, equipment and other resources, like liability insurance, responsibility roles, etc.. By definition, activity consumption is the amount of resources needed to produce one unit of an activity. So, when selecting methods and techniques to be used for an operation (making an assembly), materials, equipment and labor are quantified and, before receiving a price, a consumption is assigned to each resource. The technology used to build the respective assembly is a combination of ancillaries, end-effectors and equipment used to produce the assembly. For visualization, a flow chart is shown in Fig. 4.

In Fig. 4, ancillaries were considered furnishings and added support that do not remain in the final constructed product (assembly). They provide support either for the materials or for the activities taking place, e.g., mortar box, scaffold, concrete forms, nails and ties for false work. The end-effectors are considered devices, power tools or even parts of human body such as hands, acting upon materials, equipment or ancillaries.

A method descriptor will have ancillaries, equipment (including tools) and end-effectors. For instance, in an activity description of "backfill, structural dozer or F.E. (front-end) loader, 300' haul, sand and gravel, 75 HP (horse-power) dozer", the method descriptor is $75 \mathrm{HP}$ dozer. Using a $105 \mathrm{HP}$ dozer would represent, in this case, a different method. Other examples of method descriptors are "plywood forms (3rd uses)", "power saws" or "hydraulic cranes, 55 t capacity".

\section{Methodology-A BIM Exploratory Case Study}

The case study presented in this section relates back to the concepts of the methods descriptors explained in the previous section in order to classify the existing building methods. These would potentially be incorporated to existing parametric objects modeled with Autodesk Revit Architecture software. However,

Table 2 Methods and techniques for construction of column activity.

\begin{tabular}{llll}
\hline Assembly & Activity & Methods & Techniques \\
\hline \multirow{4}{*}{ Columns } & \multirow{2}{*}{ Forms } & Plywood & With tie wire,1st use \\
& & Aluminum & 2nd use \\
& & Steel & With tie wire \\
& & Plastic & With steel ties \\
\hline
\end{tabular}

Activity $\rightarrow$ Methods $\rightarrow$ Techniques $\rightarrow$ Resources $\rightarrow$ Resource role $\rightarrow$ Consumption (Technology)

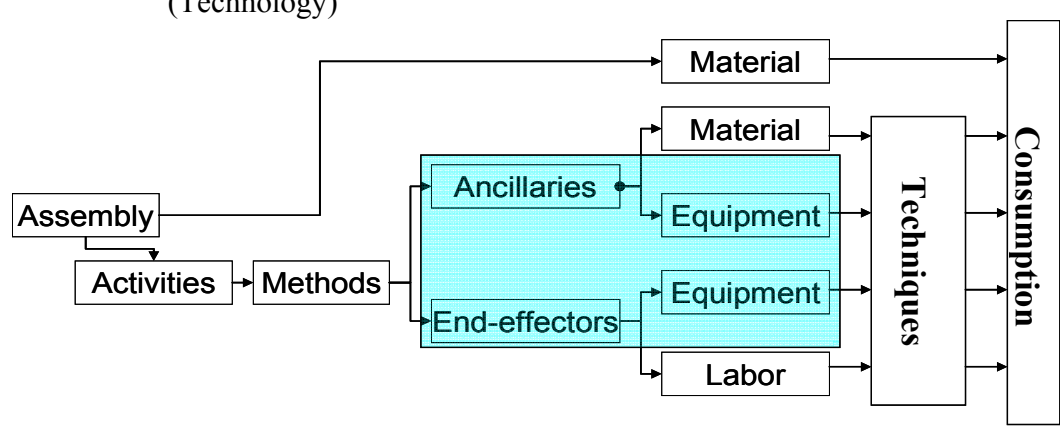

Fig. 4 Assemblies and technologies in estimating. 
because there is not yet such a functional "add-on" in the existing mentioned software, the methodology part of this research is focusing only on a BIM exploratory case study to understand the framework to obtain estimates through two different estimating procedures. To apprehend more about how owners and contractors would benefit from a better and more accurate estimate, it is essential to understand how the existing construction methods could be applied to estimating technics.

On another note, reducing the time an estimator takes to manually quantify the project, their time and expertise can be shifted towards providing a higher quality estimate, identifying construction methods and assemblies, and factoring risks. The benefits of using BIM models for cost estimation are illustrated through a construction project of a stadium expansion that was aggregated into a virtual Autodesk Revit model and derived quantities from the building materials. By having access to the projects BIM model, preparing an estimate is not only faster, but more accurate, as established later in this paper. For comparison, the study will utilize a general contractor's estimate for the stadium expansion and will compare the derived estimate to traditional methods. The quantities will be extracted from the model that has been created and compared to the general contractor's estimate that was created from OST (on screen take-off) quantifications. Through this project, the comparison of the quantity take-off obtained from the Revit model and OST will show the ease of obtaining a more accurate quantity take-off.

This section presents the findings of the study of performing the quantity take-off in Autodesk Revit and OST. In this study, The BIM model was created over imported CAD files of the stadium expansion project. There were three buildings modeled: two restroom buildings and the concession/novelty store building. The buildings were modeled with the intention of extracting quantities. The quantity estimate is only as good as the model created. Therefore, an experienced designer or modeler is required for a more accurate and thorough model. Since the design team usually provides the model, an experienced estimator with BIM experience should review it because a quantity take-off is not a basic function.

To compare the accuracy of OST method and BIM, quantities have been derived for: slab on grade, flooring, ceiling and doors. For simplicity, the quantities derived from OST for slab on grade, flooring and ceiling were input in an excel spreadsheet for easy comparison.

\subsection{Slab on Grade QTO (Quantity Take-Off) Methods}

First, a quantity is derived for the slab on grade foundation for the three buildings. The unit for slab on grade is area and volume of the concrete material. To find the quantity in OST, the estimator must trace the perimeter of the slab, as shown in Fig. 5b. Quantities given, once the perimeter is marked, can be the area and volume. To calculate the volume, the estimator must include the height of the slab, as shown in Fig. 5. Common mistakes in finding the volume are that it is calculated in CF (cubic foot) instead of CY (cubic yard) or the height is not entered correctly. In Revit, the estimator must ensure that the object drawn is inclusive of all desired areas. In order to calculate the quantity, the user creates a material take-off and selects floor then he/she includes the family and type, area and volume. The user must insure that the unit is correct for the volume (i.e., $\mathrm{CY}$ not $\mathrm{CF}$ ). Once you are finished organizing and creating your table, the quantity is automatically calculated from the model, as shown in Table 3. It then can be exported to MS Excel.

\subsection{Flooring QTO Methods}

Additional information can be derived from the floor material take-off in Revit. Since the buildings had two types of flooring (carpet and sealed concrete), the flooring quantity can be taken from the same schedule as the slab on grade (Table 4). To calculate the quantity for sealed concrete, you must take the area of the 5" 


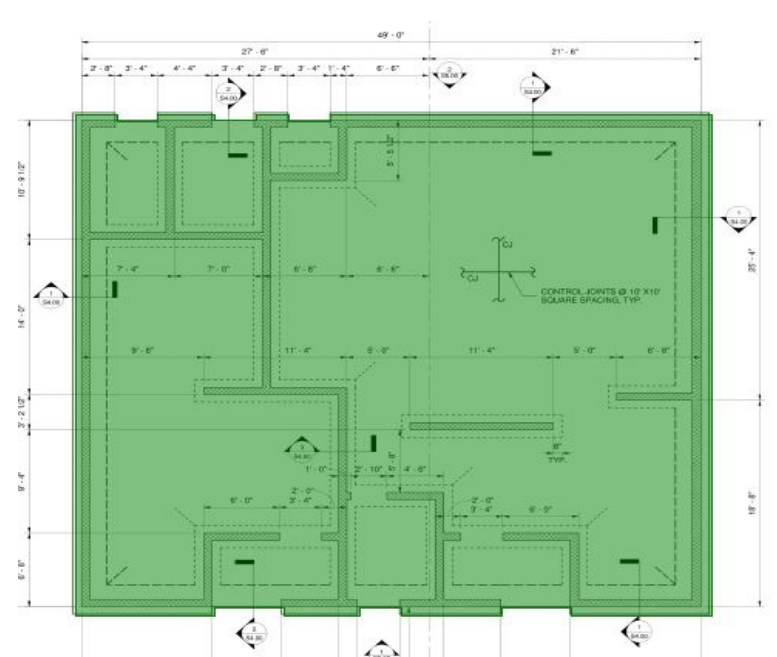

(a)

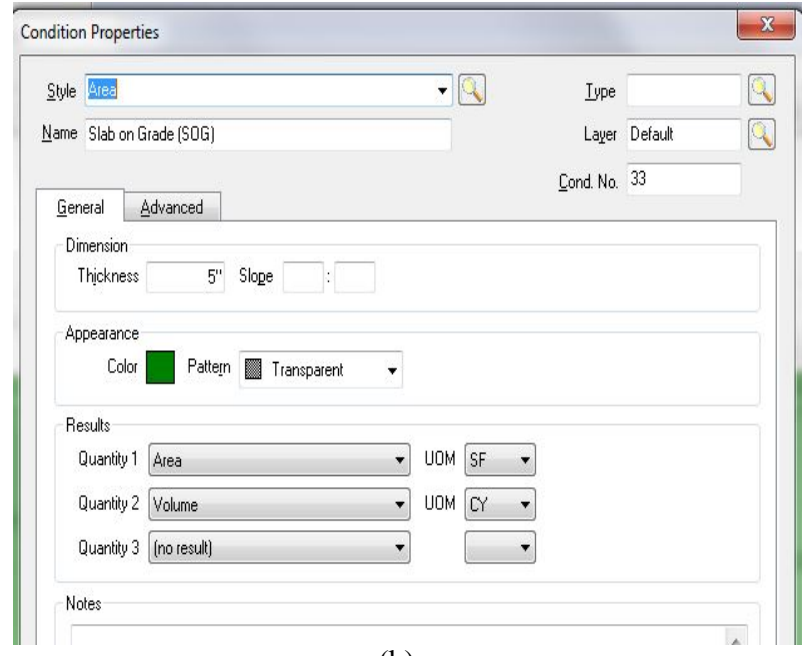

(b)

Fig. 5 (a) Slab on grade and (b) condition properties in OST software.

Table 3 Revit flooring material take-off.

\begin{tabular}{llllll}
\hline Family and type & Area & Assembly description & Family & Material: volume & Volume \\
\hline Floor: 5" concrete & $2,000 \mathrm{SF}$ (square feet) & Floor construction & Floor & $833.27 \mathrm{CF}$ & $30.86 \mathrm{CY}$ \\
Floor: 5" concrete & $3,618 \mathrm{SF}$ & Floor construction & Floor & $1,507.43 \mathrm{CF}$ & $55.83 \mathrm{CY}$ \\
Floor: 5" concrete & $1,986 \mathrm{SF}$ & Floor construction & Floor & $827.54 \mathrm{CF}$ & $30.65 \mathrm{CY}$ \\
Floor: 5" concrete: 3 & - & - & - & - & - \\
Floor: carpet tile & $1,031 \mathrm{SF}$ & Floor construction & Floor & $10.74 \mathrm{CF}$ & $0.40 \mathrm{CY}$ \\
Floor: carpet tile: 1 & - & - & - & - & - \\
\hline
\end{tabular}

Table 4 OST flooring take-off.

\begin{tabular}{lll}
\hline Flooring & QTY & Unit \\
\hline Type 1 (sealed concrete) & 6551 & SF \\
Type 2 (carpet) & 44 & SY \\
\hline
\end{tabular}

concrete and subtract the area of the carpet. The carpet area is automatically calculated. Common mistakes when calculating the quantity for carpet are to ensure the correct unit. Some estimators calculate the area in different units (i.e., square foot and square yard).

To calculate the area in OST, it is necessary to trace the perimeter of the rooms of each type of flooring (Fig. 6). Ensuring the unit is correct for each one (i.e., sealed concrete is SF and carpet SY). Multiple units can be calculated from the condition properties as shown in Fig. 5.

\subsection{Ceiling QTO Methods}

Similar to flooring, the ceiling is a simple take-off. For OST, the estimator must trace around the room for each type of ceiling (Fig. 7). The unit for ceiling types is SF. In OST, the user should ensure that each type is taken off separately.

In Revit, we simply create a schedule and select ceiling. Select the columns you would wish to have on the schedule as well as how you would like it sorted (i.e., sorted by type) and calculate totals for each. Once the schedule is created, the estimator will have an automatic quantity for each type of ceiling. For this project, there are only three types of ceilings: ACT-1, ACT-2 and stainless steel panels. All other areas are open to structure.

As indicated in Table 5, the OST take-off numbers are comparable to the quantities derived from the model. There is a $5.5 \%$ increase in quantity from the OST take-off to the quantity from the model, therefore the model obtained was more accurate relative to the accounted quantities of the ceiling materials that are needed in the construction phase to be placed. If the level of detail input in Revit for all parametric objects created in the respective model is considered at the 


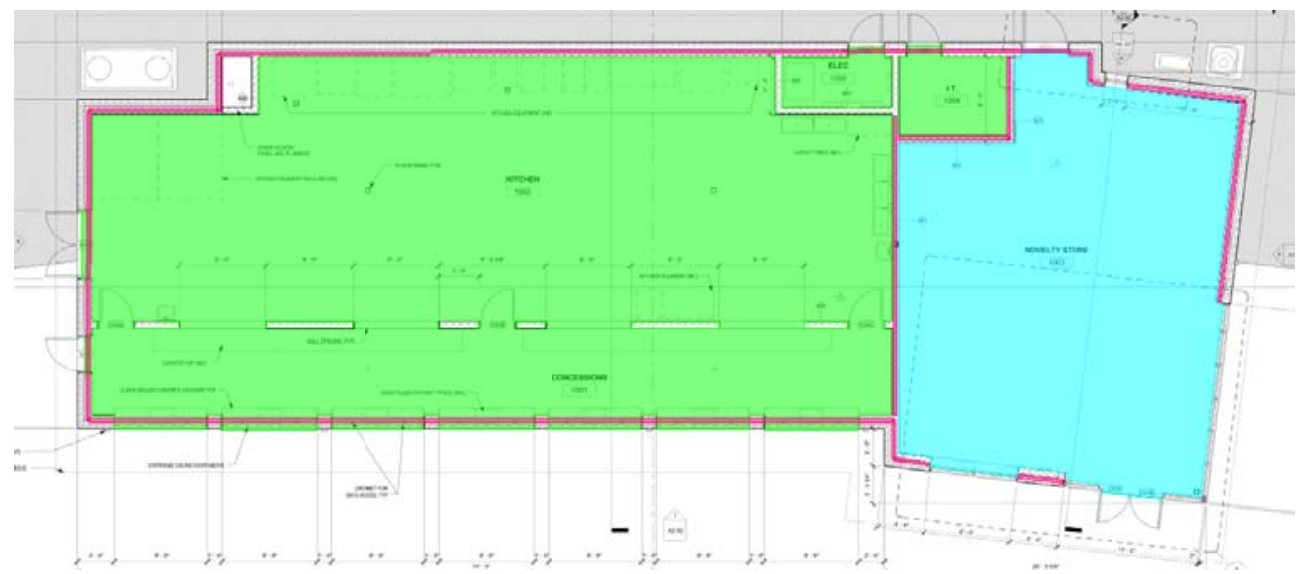

Fig. 6 OST flooring take-off.

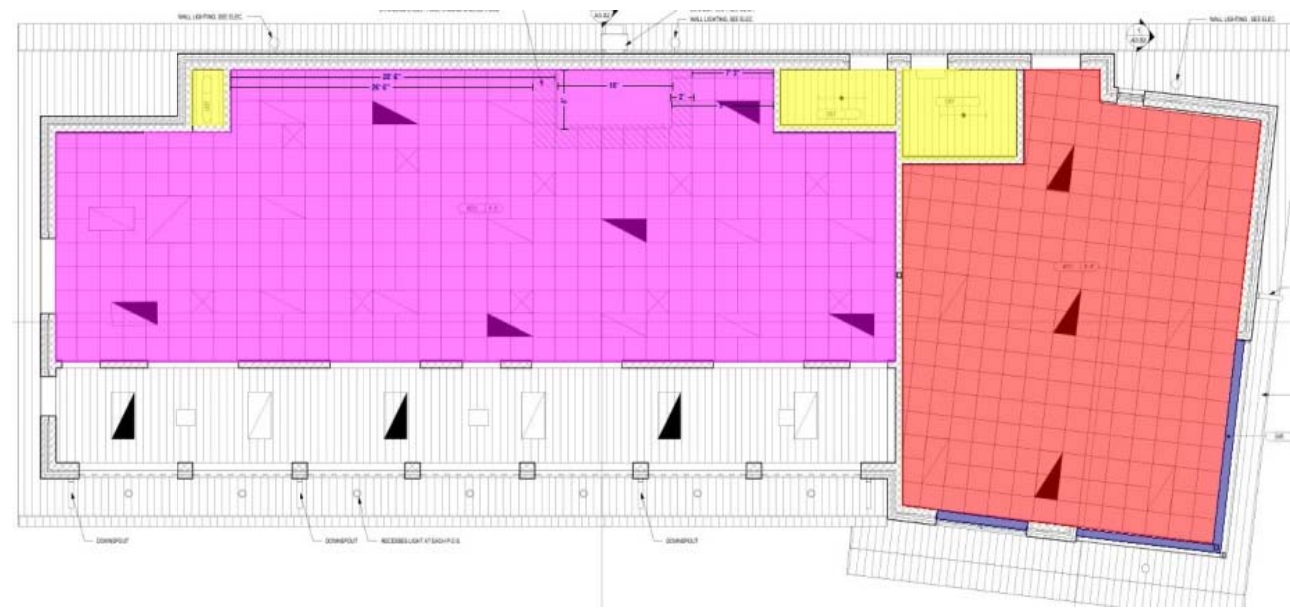

Fig. 7 OST ceiling material take-off.

Table 5 OST ceiling material take-off and Revit ceiling material take-off.

\begin{tabular}{llll}
\hline Category & Activity name & Quantity & Unit \\
\hline Acoustical ceiling tile & - & - & - \\
- & ACT-1 & 1,008 & SF \\
- & ACT-2 & 1,685 & SF \\
- & Stainless steel ceiling panel & 47 & SF \\
\hline Ceiling schedule & & & Area \\
\hline Family and type & Assembly name & Assembly description & 1,592 SF \\
Basic ceiling: ACT-2 & - & Ceiling finish & 1,006 SF \\
Basic ceiling: ACT-1 & - & Ceiling finish & $29 \mathrm{SF}$ \\
Compound ceiling: GWB (gypsum wall & - & Suspended & $45 \mathrm{SF}$ \\
board) on Mtl Stud & - & Ceiling finish & \\
Basic ceiling: SS (stainless steel) panel & - & & \\
\hline
\end{tabular}

front-end of the project for quantity take-off purposes, it is very possible to obtain higher accuracies when doing the take-offs. This $5.5 \%$ can possibly add up to be a costly mistake when competitively bidding on a project, which is why it is important to accurately estimate a job thoroughly. By having different methods of estimating, it also insures that the estimator is getting a more accurate quantity by double checking the numbers. Furthermore, considering the right construction methods within an estimate will assure the high accuracy when a cost estimate is in sought for a precise bid. 


\section{Discussions and Conclusions}

When comparing the two procedures, the time on task was a lot less when using the model to extract quantities and the accuracy of the quote was more precise. In the study conducted by Alder [8], those using the BIM method had (on average) a percentage of error of $1 \%$ for this take-off, whereas on-screen take-off, users had a $3 \%$ error. To draw a better conclusion from this specific study, more tests need to be conducted to determine the accuracy on the two procedures. The study is limited to only certain building elements defined and relatively encompassing application of the construction methods. Other limitations of the study would be the level of details in Revit for the parametric objects created in the initial model. Utilization of the program provides many benefits to the entire project team (i.e., clients/owners, designers, contractors and subcontractors).

Further research should be conducted to compare estimates generated by the two procedures: OST from construction plans and detailed models generated from CAD files and structural plans. A more complete study would include take-off performed by an experienced professional estimator, a BIM model created by a professional designer, and an experienced estimator that is familiar with the BIM quantity take-off tools and available construction methods in a specific company. The technologies available in a company setting would add value to the study because methods selection used in estimating process would illustrate a certain difference in obtaining estimate accuracy. The totality of these technologies and the resource allocation make up the domain for estimate optimization. Selecting the right methods based on method descriptors, using one of the technologies available for multiple activities would create accurate costs when not only materials are priced, but also right equipment and available labor. Through method selection, technologies for the site assemblies are selected. As a counterexample, for backfill and/or excavation activity, the estimator can choose to bring three different types of equipment to the site. A further consideration related to quality optimization of the work or safety procedures for construction people in the site makes the actual scope or purpose of the optimization. Depending on the scope of optimization, they can use: backhoe loader-48 HP, dozer-105 HP or dozer-75 HP (as an example).

\section{Recommendations for Further Studies}

Graphical representation in Fig. 2 is an attempt to create a better description of the concept map of estimates, so the first recommendation for further research is to acquire a more precise representation through more case studies. The present representation is comprised on the approach that there is an influence of using various construction methods reflected in the expected relative accuracy of estimating. The existing relationships between the items or assemblies generated in a new estimate from BIM and a specific technology built within the estimate, and recalled from various databases of the estimate, are beyond the scope of this research. Once details of relationships are known, construction methods and available technologies can be automatically aggregated and computationally integrated into activities, therefore, the whole construction process can be optimized for time, cost, quality or safety.

Another recommendation for further research is the actual domain of estimate optimization. The optimization of the estimate, based on the technology ontology, was not the purpose of this study. However, a series of new research studies, pertaining to the scope of optimization, can be undertaken for further development. Creating opportunities for an in-depth understanding of the estimating procedures and techniques is supportive to the process of correctly determining the construction methods applicable to a particular project based on methods descriptors defined in this research. In this sense, owners can efficiently demand deliverables that can be utilized by them downstream, allowing most of the contractors and their subcontracting trades to work efficiently and to assure 
the necessary flow of operations during various construction phases.

\section{References}

[1] M. Dell'Isola, Detailed Cost Estimating: The Architect's Handbook of Professional Practice, 2003 ed., [Online], 2003, http://www.aia.org/aiaucmp/groups/aia/ documents/pdf/aiab089228.pdf (accessed July 1, 2014).

[2] L. Sabol, Challenges in Cost Estimating with Building Information Modeling, Design + Construction Strategies, LLC [Online], Washington DC, 2008, http://www.dc strategies.net/files/2_sabol_cost_estimating.pdf (accessed July 1, 2014).

[3] S. Azhar, M. Hein, B. Sketo, Building information modeling (BIM): Benefits, risks and challenges, in: Proceedings of the 44th Associated Schools of Construction National Conference, 2008, pp. 360-368.
[4] F. Cheung, J. Rihan, J. Tah, D. Duce, E. Kurul, Early stage multi-level cost estimation for schematic BIM models, Automation in Construction 27 (2012) 67-77.

[5] Revit BIM [Online], 2007, http://www.consortech.com/ bim2/documents/BIM_cost_estimating_EN.pdf (accessed July 1, 2014).

[6] M. Niknam, S. Karshenas, A semantic web service approach to construction cost estimating, in: Computer in Civil Engineering Proceedings 2013, 2013, pp. 484-491.

[7] S. Xu, K. Liu, L. Tang, Cost estimation in building information model, in: Proceedings of International Conference on Construction and Real Estate Management, 2013, pp. 555-566.

[8] M.A. Alder, Comparing time and accuracy of building information modeling to on-screen takeoff for a quantity takeoff of a conceptual estimate, Doctoral Dissertation, Brigham Young University, 2006. 